\section{Attempts to Modify the Normal Metabolism of Strontium-90 in Rats}

Iто et $a l .{ }^{1}$ and Lindenbaum ${ }^{2}$ injected the sodium or potassium salt of rhodizonic acid in order to increase the excretion of strontium-90 in rats. The former observed a slowing, the latter an acceleration in the elimination of strontium-90. We found that sodium rhodizonate given parenterally slows the removal of strontium-90 from the body, mainly by depressing the urinary excretion of radiostrontium. The effect was dependent upon the amount of rhodizonate injected (Fig. 1).

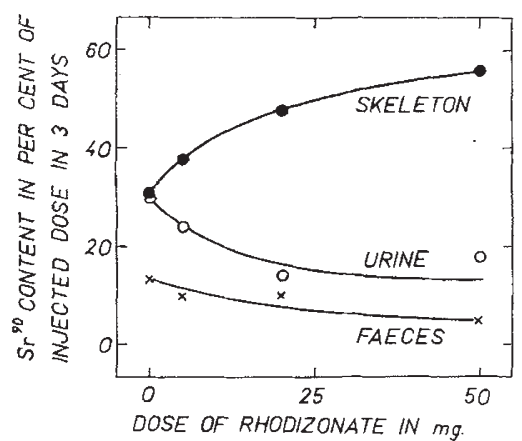

Fig. 1. Effect of rhodizonate on retention and excretion of strontium-90 in the rat. Each point represents mean from 5 rats in control group and from 2 rats each for three treated groups Total skeletal content was calculated by multiplying the content of both femurs by a factor of ten. Each animal received abou $2 \mu \mathrm{c}$. of strontium-90 with $0.5 \mathrm{mgm}$. of strontium chloride carrier.

In further preliminary experiments we tried to modify the fæcal excretion of strontium-90. In the first study we injected strontium-90 intraperitoneally and administered barium sulphate or tertiary calcium phosphate orally one hour before and immediately before strontium-90 injection. The amount of strontium-90 found in the fæces of the treated group after 72 hours was about 50 per cent above the control levels. The urinary excretion of strontium-90 remained unchanged after barium sulphate, but after the administration of calcium phosphate less stront. ium.90 was excreted in urine. The total radiostrontium excretion in both cases did not change essentially. Therefore, another experiment was performed where zirconium citrate, which is known to stimulate the urinary excretion of radiostrontium ${ }^{3,4}$ was administered intraperitoneally half-an-hour before strontium-90, together with tertiary calcium phosphate, given orally one hour before and immedi-

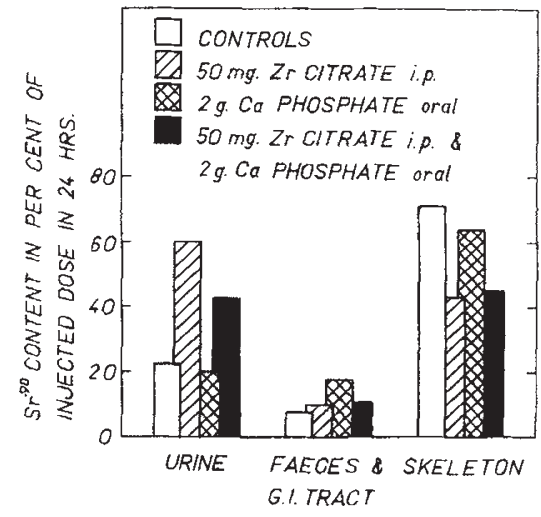

Fig. 2. Effect of tertiary calcium phosphate and zircouium citrate on retention and excretion of $B$ trontium-90 in the rat values are expressed as mean of 3 rats per group. Total skeletal content was calculated by multiplying the content of both femurs hy a factor of ten. Each animal received intraperitoneally about $2 \mu \mathrm{c}$. of strontium- 90 with $0.5 \mathrm{mgm}$. of strontium chloride carrier. ately before strontium-90. Radiostrontium was injected subcutaneously to prevent its forming a direct complex with zirconium eitrate in the peritoneal cavity. The results are shown in Fig. 2. The effect of zirconium citrate in promoting excretion of strontium-90 in urine was predominant, but calcium phosphate did not stimulate freal excretion of strontium-90 when administered in combination with zirconium citrate. The effectiveness of calcium phosphate given alone in increasing the excretion of radiostrontium through the gut was confirmed in the present experiment.

Finally, we studied the possibility of decreasing the intestinal absorption of strontium-90 using tertiary calcium phosphate. Strontium-90 was given to fasting animals by stomach tube, followed immediately by the calcium phosphate suspension, administered in the same way. Only 13 per cent and 25 per cent of the strontium-90 administered was found in the femurs of the treated animals after 4 hours and 8 days respectively, as comparing with the controls. This is even less than in the similar experiments of MacDonald et al. ${ }^{5}$, who used tertiary sodium phosphate.

Thus, in the experiments described using barium sulphate and tertiary calcium phosphate, we were able to modify the transfer of strontium-90 through the intestinal wall; promoting the elimination of absorbed strontium-90 from the blood to the gut and its excretion with the stools, and diminishing the absorption of strontium-90 from the gut to the blood and its deposition in the bones. For this purpose it would also be possible to use other unabsorbable materials, for example, complexing agents, which cannot be given parenterally.

The details of this work will be published elsewhere. V. VolF

Institute of Industrial Hygiene

and Occupational Diseases,

Prague.

July 27.

' Ito, J., Tsurufuji, S., Ishidate, M., Tamure, Z., and Takite, H., J. Pharm. Soc. Japan, 76, 1406 (1956).

${ }^{2}$ Lindenbaum, A., ANL, 5732, 134 (1957). ${ }^{3}$ Cohn, S. H., and Gong, J. K., Proc. Soc. Exp. Biol. Med., 83, 550 4 Schubert, J., and Wallace, H. jun., J. Biol. Chem., 183, $157(1950)$.
6 MacDonald, N. S., Spair, P. C., Ezmirlian, F., and Rounds, D. E., MacDonald, N. S., Spair, P.
$\quad$ J. Nutrit., $57,555(1957)$.

\section{Role of Magnesium in the Insulin-Sensitivity of the Rat Diaphragm in vitro}

IT was reported earlier ${ }^{1}$ that insulin increases the uptake of glucose by the isolated rat diaphragm only in the presence of moderate amounts of certain metallic ions, such as sodium, potassium, rubidium, cæsium and magnesium. The present communication reports the results of some further experiments which stress the importance of the magnesium ion with respect to the insulin-sensitivity of the rat diaphragm.

Diaphragms from overnight fasted rats (weight 100-120 gm.) were first incubated for $\frac{1}{2}$ hour in media of different compositions without any added substrate. The effect of this pre-incubation on the insulinsensitivity of the tissue, as measured by increased uptake of glucose in the presence of insulin from Geys' salt mixture ${ }^{2}$, was then tested. Both the initial and final incubations were carried out under aerobie conditions.

The results given in Table 1 show that insulin caused the usual increase in the uptake of glucose by a diaphragm which had been pre-incubated for $\frac{1}{2}$ hour in Geys' buffer either at room temperature $\left(20^{\circ} \mathrm{C}\right.$.) 